\title{
Antioxidant, Antiinflamatory, and Antiproliferative Activities of Strawberry Extracts
}

\author{
Ji-Young Hong ${ }^{1}$, Su-Hyun Song ${ }^{1}$, Hyen Joo PaRK ${ }^{1}$, Yong-Jin $\mathrm{CHO}^{2}$, \\ Jae-Ho PYEE ${ }^{3}$, and Sang Kook LeE ${ }^{1} *$ \\ ${ }^{1}$ College of Pharmacy, Ewha Womans University, 11-1 Daehyun-dong, Seodaemun-ku, Seoul 120-750, Korea \\ ${ }^{2}$ Food Nano-Biotechnology Research Center, Korea Food Research Institute, \\ 516 Baekyun-dong, Bundang-ku, Sungnam-si, Gyeonggi-do 463-746, Korea \\ ${ }^{3}$ College of Natural Sciences, Dankook University, 126 Jukjeon-dong, Suji-ku, Yongin-si, Gyeonggi-do 448-701, Korea
}

(Received April 21, 2008; Revised July 29, 2008; Accepted August 8, 2008)

\begin{abstract}
Strawberry is widely consumed in diet and has been attracted much attention due to its potential for human health benefits. Strawberry contains a diverse range of phytochemicals but the biological activities with molecular mechanisms are poorly elucidated yet. In this study, the effects of the extracts of strawberry (Maehyang cultivar) on antioxidant, antiinflammatory, and antiproliferative potential against various cancer cells were investigated. The strawberry extracts (SE) of Maehyang cultivar showed 1,1-diphenyl-2-picrylhydrazyl (DPPH) free radical scavenging activities. In addition, SE inhibited the growth of human colon (HCT-116), lung (A549), stomach (SNU-638) and fibrosarcoma (HT-1080) cancer cells. The strawberry extracts also exhibited the inhibitory effect on lipopolysaccharide (LPS)-stimulated nitric oxide (NO) production and suppressed LPS-induced inducible nitric oxide synthase (iNOS) protein and mRNA expression in mouse macrophage RAW 264.7 cells. These findings suggest that the strawberry extracts (Maehyang cultivar) might have antioxidant, antiinflammotry, and anticancer activities.
\end{abstract}

Keywords: Strawberry, Maehyang, Antioxidant, Anti-inflammation, Nitric oxide, Antiproliferation of cancer cells

\section{INTRODUCTION}

Epidemiological studies suggest that a high dietary intake of fruits and vegetables is strongly associated with the alleviation of incidence of cardiovascular, degenerative diseases, and cancer (Meysken and Szabo, 2005; Steinmetz and Potter, 1991; Temple, 2000; Willett, 1994). Strawberry (Fragariaxananassa Duch.) is one of the most commonly consumed berries. Together with other soft fruit, it is important dietary source of fiber and bioactive compounds both micronutrients and phytochemicals. In particular, strawberry has a diverse range of phytochemicals, especially phenolic compounds such as phenolic acids (hydroxybenzoic acids, hydroxycinnamic acids), ellagic acid, and flavonoids (anthocyanin, catechin, quercetin and kaempferol), which contribute to its biological properties including antioxidant, anticancer, and cancer chemopreventive activities (Das, 1994; Heinonen

\footnotetext{
${ }^{*}$ Corresponding author

Tel: +82-2-3277-3023, Fax: +82-2-3277-2851

E-mail: sklee@ewha.ac.kr
}

et al., 1998; Sun et al., 2002; Vinson et al., 2001; Wang et al., 1997).

A body of evidences suggest that reactive oxygen species (ROS) and pro-inflammatory mediators such as NO are closely implicated in various pathological processes, including atherosclerosis, several degenerative diseases, and cancer (Ames et al., 1993; Dreher and Junod, 1998; Kröncke et al., 1998; Patel et al., 2000). Although these molecules have been known to mediate tissue homeostasis and cellular signal transduction (Lander, 1997), they can also participate in various pathological conditions. For example, sustained damages of DNA, cell membrane, and protein, which are caused by ROS, can initiate and promote the transformation of normal cells to cancerous cells (Dreher and Jonod, 1998). In addition, NO has also been implicated in a variety of pathophysiological conditions including atherosclerosis, inflammation, and carcinogenesis (Kröncke et al., 1998; Ohshima and Bartsch, 1994). Since inducible nitric oxide synthase (iNOS) is responsible for the overproduction of NO in inflammation, iNOS has been attracted as a target to develop new substances for the treatments of chronic inflammatory 
diseases (Hobbs et al., 1999). NO synthesized by iNOS has also been considered as an important mediator of carcinogenesis. NO can react with reactive oxygen species and then produce reactive nitrogen species contributed to DNA damage and mutagenesis (Wiseman and Halliwell, 1996). Thus, compounds that modulate the production or activity of ROS and NO, including free radical scavengers, and inhibitors of iNOS, might be considered as cancer chemopreventive agents.

Maehyang is a cross-fertilized cultivar between Dochinomine and Akihme, first produced at Nonsan strawberry experiment station in 1997. It is a valuable Korean domestic cultivar with excellent flavor, fragrance, and saccharinity. However, the biological activities of Maehyang have not been reported yet. Thus, in the present study, we evaluated the chemopreventive potential of Maehyang with antioxidant, antiinflammatory, and antiproliferative activities against human cancer cells. This study exclusively demonstrates the beneficial effects of strawberry (Meahyang) in human health and disease prevention.

\section{MATERIALS AND METHODS}

\section{Chemicals}

Dulbecco's Modified Eagle medium (DMEM), Roswell Park Memorial Institute medium 1640 (RPMl 1640 medium), fetal bovine serum (FBS), antibiotics-antimycotics solution, and trypsin-EDTA were purchased from Invitrogen (Grand Island, NY, USA). 1,1-diphenyl-2-picrylhydrazyl (DPPH), vitamin C, lipopolysaccharide (LPS, E. coli 0111:B4), $N$-(1-naphthyl)ethylnenediamine dihydrochloride, sulfanilamide, sulforhodamin B (SRB), trichloroacetic acid, TRI reagent, sodium nitrite, ellipticine, and 3-(4,5dimethylthiazol-2-yl)-2,5-diphenyltetrazolium bromide (MTT), mouse monoclonal anti- $\beta$-actin were purchased from Sigma (St. Louis, MO, USA). Rabbit polyclonal anti-iNOS was purchased from Santa Cruz Biotechnology (Santa Cruz, CA, USA).

\section{Cell culture}

Murine macrophage RAW 264.7 cells, human lung carcinoma (A549), colorectal carcinoma (HCT-116), fibrosarcoma (HT1080), and stomach adenocarcinoma (SNU638) cells were obtained from American Type Culture Collection (ATCC, Manassas, VA, USA) or Korean Cell Line Bank (KCLB, Seoul, Korea). RAW 264.7 and HT1080 cells were cultured in DMEM. HCT-116, SNU-638, and A549 cells were cultured in RPMI 1640 medium. All media were supplemented with $10 \%$ heat-inactivated FBS and antibiotics. All cells were incubated at $37^{\circ} \mathrm{C}, 5 \%$
$\mathrm{CO}_{2}$ in the humidified atmosphere.

\section{Preparation of test materials}

After removing the stalk, Maehyang strawberries were pulverized, and then methanol were added to pulverized strawberry in the ratio of $270 \mathrm{~g}$ of strawberries with $1 \mathrm{~L}$ of solvent. The suspension was sonicated for $10 \mathrm{~min}$ and then filtered. The filtrate was concentrated in vacuum to afford a residue and stored at $-20^{\circ} \mathrm{C}$ (Moist content of the strawberry: $92.2 \%, \mathrm{MeOH} /$ strawberry=3.7 $\mathrm{mL} / \mathrm{g}$ ).

\section{Evaluation of the antioxidant potential of test mate- rials (DPPH)}

The antioxidant properties of test materials were evaluated by 1,1-diphenyl-2-picrylhydrazyl (DPPH) free radical scavenging activity (Lee et al., 1998). Test materials, dissolved in DMSO, were incubated with $300 \mu \mathrm{M}$ of DPPH ethanol solution at $37^{\circ} \mathrm{C}$ for $30 \mathrm{~min}$ in 96 well plates. The absorbance was measured at $515 \mathrm{~nm}$. \% of inhibition, the degree of radical scavenging by test groups, was determined by comparison with vehicle-treated control group. $\mathrm{IC}_{50}$ values, which denote the concentration of test samples for bringing to scavenge $50 \%$ of DPPH radicals, were calculated using non-linear regression analysis (\% inhibition versus concentration). Vitamin $\mathrm{C}$ was used as positive control.

\section{Antiproliferative effect of cancer cell growth}

To evaluate the anti-proliferative potential of test materials against various human cancer cells, sulforhodamine $B$ assay (SRB assay) was performed according to the previously reported procedure with some modifications (Skehan et al., 1990). Cells $\left(1 \times 10^{4}\right.$ cells/well) were plated in 96 well plates with various concentrations of test materials. After 3 day incubations, cells were fixed with $10 \%$ trichloroacetic acid solution for $30 \mathrm{~min}$ at $4^{\circ} \mathrm{C}$, washed five times with tap water, and dried in the air. Thereafter, cells were stained with $0.4 \%$ SRB in $1 \%$ acetic acid solution for $1 \mathrm{~h}$ at room temperature. Unbound cells were washed out by $1 \%$ acetic acid, SRB bound cells were solubilized $10 \mathrm{mM}$ Tris (pH 10.0), and absorbance was measured at $515 \mathrm{~nm}$. The result was expressed as a percentage, relative to solvent-treated control incubations, and the $\mathrm{IC}_{50}$ values were calculated using non-linear regression analysis (percent survival versus concentration).

\section{Nitrate assay}

To evaluate the inhibitory activity of test materials on LPS-induced NO production, RAW 264.7 cells in 10\% FBS-DMEM without phenol red were plated in 24 well 
plates $\left(5 \times 10^{5} \mathrm{cells} / \mathrm{ml}\right)$, and incubated for $24 \mathrm{~h}$. After incubation, cells were washed with PBS. Replaced with fresh media, and then incubated with $1 \mu \mathrm{g} / \mathrm{ml}$ of LPS in a presence or absence of test samples. After additional $20 \mathrm{~h}$ incubation, the media were collected and analyzed for nitrite accumulation as indicator of NO production by the Griess reaction (Green et al., 1982). Briefly, $180 \mu \mathrm{l}$ of Griess reagents $(0.1 \% \quad \mathrm{~N}$-(1-naphthyl)ethyl-enediamine dihydrochloride in $\mathrm{H}_{2} \mathrm{O}$ and $1 \%$ sulfanilamide in $5 \%$ $\mathrm{H}_{3} \mathrm{PO}_{4}$ ) were added to $100 \mu \mathrm{l}$ of each supernatant from LPS or sample-treated cells in 96 well plates. The absorbance was measured at $540 \mathrm{~nm}$ using microplate reader (Bio-Rad Laboratories, Hercules, CA, USA), and nitrite concentration was determined by comparison with a sodium nitrite standard curve. \% Inhibition was expressed as [1-(NO level of test samples/NO levels of vehicletreated control)] $\times 100$. The $\mathrm{IC}_{50}$ value, the sample concentration resulting in $50 \%$ inhibition of NO production, was determined using non-linear regression analysis $(\%$ inhibition versus concentration). $\mathrm{N}^{\mathrm{G}}$-monomethyl-L-arginine (L-NMMA) was used as a positive control.

\section{MTT assay}

To examine whether the inhibitory effects of test samples on LPS-induced NO production were related to their cytotoxicity, cell viability was determined directly by the mitochondrial-dependent reduction of MTT to formazan (Alley et al., 1988) in this assay system. After Griess reaction, MTT solution was added to the media (final 500 $\mu \mathrm{g} / \mathrm{ml}$ ) and then incubated at $37^{\circ} \mathrm{C}$ for $4 \mathrm{~h}$. The media were discarded, $1 \mathrm{ml}$ of DMSO was added each well to dissolve the formazan, and then absorbance was measured at $570 \mathrm{~nm}$.

\section{Reverse transcriptase-polymerase chain reaction (RT-PCR)}

RAW 264.7 cells were stimulated with $1 \mu \mathrm{g} / \mathrm{ml}$ LPS in a presence or absence of test sample for $4 \mathrm{~h}$. Total cellular RNA was extracted with TRI reagent (Sigma) according to the manufacturer's recommended procedure. About 1 $\mu \mathrm{g}$ of total RNA was reverse-transcribed using oligo-(dT) ${ }_{15}$ primers and avian myeloblastosis virus reverse transcriptase (Promega, Madison, WI, USA). PCR was performed in a reaction mixture containing the obtained cDNA, $0.2 \mathrm{mM}$ dNTP mixture (Promega), 10 pmol of target gene-specific primers, and 0.25 unit of Taq DNA polymerase (Promega) using GeneAmp PCR system 2400 (Applied Biosystems, Foster, CA, USA). The sense and antisense primers for iNOS were 5-ATGTCCGAAGCAAACATCAC-3 and 5-TAATGTCCAGGAAGTAGGTG-
3 , respectively. The sense and antisense primers for $\beta$ actin were 5-TGTGATGGTGGGAATGGGTCAG-3 and 5TTTGATGTCACGCACGATTTCC-3, respectively. Each of PCR steps was performed as follows: initial denaturation step for 4 min at $94^{\circ} \mathrm{C} ; 25-30$ cycles of amplification step consisting denaturation for $30 \mathrm{~s}$ at $94^{\circ} \mathrm{C}$, annealing for 30 $\mathrm{s}$ at $55^{\circ} \mathrm{C}$, and elongation for $30 \mathrm{~s}$ at $72^{\circ} \mathrm{C}$; and final extension step for $5 \mathrm{~min}$ at $72^{\circ} \mathrm{C}$. PCR products were separated by $2 \%$ agarose gel electrophoresis, stained with SYBR-Gold (Molecular Probes, Eugene, Oregon, USA), and visualized by UV transillumination.

\section{Western blot}

Cells were seeded into $60 \mathrm{~mm}$ dishes at density of $3 \times 10^{5}$ cells/dish. After $24 \mathrm{~h}$ incubation, cells were treated with test samples for the indicated times. Harvested cells were washed with PBS, suspended with boiling $2 \times$ sample loading buffer (250 mM Tris- $\mathrm{HCl}$ (pH 6.8), 4\% SDS, 10\% glycerol, $0.006 \%$ bromophenol blue, $2 \% \beta$-mercaptoetha$\mathrm{nol}, 50 \mathrm{mM}$ sodium fluoride, and $5 \mathrm{mM}$ sodium orthovanadate) and further incubated for $5 \mathrm{~min}$ at $100^{\circ} \mathrm{C}$ for complete lysis. Equal amount ( 40 or $80 \mu \mathrm{g}$ ) of protein samples were subjected to $6 \sim 15 \%$ SDS-PAGE. Separated proteins were electrically transferred onto PVDF membranes (Milipore, Bedford, MA, USA). Membranes were blocked with blocking buffer ( $5 \%$ non-fat dry milk in PBS containing $0.1 \%$ Tween-20 (PBST)) for $1 \mathrm{~h}$ at room temperature. After washing three times with PBST, membranes were incubated with primary antibodies diluted in $3 \%$ non-fat diary milk in PBST (1:200 1:2000) overnight at $4^{\circ} \mathrm{C}$. Membranes were washed three times with PBST, and incubated with corresponding secondary antibodies diluted in 3\% non-fat dry milk in PBST (1:1000 1:5000) for $2 \mathrm{~h}$ at room temperature. Membranes were washed three times with PBST, and then exposed to enhanced chemiluminescence (ECL) detection kit (LabFrontier, Suwon, Korea). Blots were detected by LAS 3000 (Fuji Film Corp., Japan).

\section{Statistics}

All experiments were repeated at least three times. Data were presented as means \pm S.E.M. for the indicated number of independently performed experiments. Student's t-test was used for the determination of statistical significance. $P<0.05$ was considered significant.

\section{RESULTS}

\section{Antioxidant effects of strawberry extracts (SE)}

We examined antioxidant potential of strawberry extract 


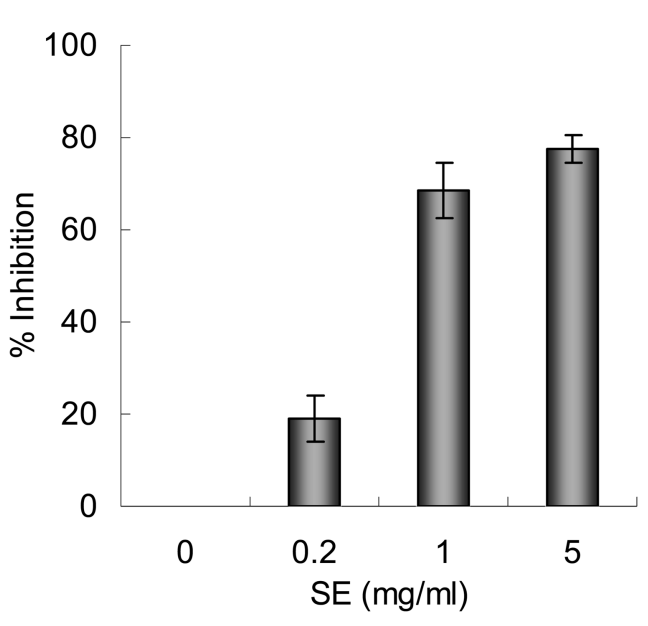

Fig. 1. DPPH free radical scavenging activity of strawberry extracts (SE). Strawberry extracts (SE) were incubated with $300 \mu \mathrm{M}$ of DPPH ethanol solution at $37^{\circ} \mathrm{C}$ for $30 \mathrm{~min}$. The absorbance was measured at $515 \mathrm{~nm}$, and DPPH radical scavenging activity of each sample was determined in comparison with vehicle-treated control group.

of Maehyang cultivar by the use of DPPH that stably generates free radicals in ethanol solution. As shown in Fig. 1 , strawberry extracts (SE) exhibited radical scavenging activities in a dose-dependant manner with an $\mathrm{IC}_{50}$ value of $0.75 \mathrm{mg} / \mathrm{ml}$. Vitamin $\mathrm{C}$, a positive control, showed $\mathrm{IC}_{50}$ value of $21.9 \mu \mathrm{g} / \mathrm{ml}$ in this assay system. The result suggests that SE may possess antioxidant potential by scavenging free radical generation.

\section{Inhibitory effects on the proliferation of human can- cer cells}

The growth inhibitory potential of SE was determined in cultured human cancer cell lines by a colorimetric SRB protein dye staining method. The results were expressed as a percentage, relative to control cell number, indicating the extent of growth inhibitory effect of the test material SE. As summarized in Table I and Fig. 2, SE has antiproliferative effects against the various tested cancer cell lines. Among tested cell lines, SE showed the most potent inhibitory activity in human fibrosarcoma HT1080 cells.

\section{Anti-inflammatory effects of strawberry extracts}

The effect of SE on LPS-induced NO production was examined in RAW 264.7 cells. Nitrite, the stable metabolite of $\mathrm{NO}$ and used as an indicator for $\mathrm{NO}$ production, was monitored in cultured LPS-stimulated RAW 264.7 cells. LPS $(1 \mu \mathrm{g} / \mathrm{ml})$ markedly increased the production of NO from the basal level of $1.4 \pm 0.1 \mu \mathrm{M}$ to $34.0 \pm 1.1 \mu \mathrm{M}$ for $20 \mathrm{~h}$ incubation. In this assay system, L-NMMA, a
Table I. Anti-proliferative activity of the strawberry extracts (SE) against human cancer cell lines.

\begin{tabular}{ccc}
\hline & \multicolumn{2}{c}{$\mathrm{IC}_{50}$} \\
\cline { 2 - 3 } & $\mathrm{SE}(\mathrm{mg} / \mathrm{ml})$ & Ellipticine $(\mu \mathrm{M})$ \\
\hline A549 & 7.7 & 1.1 \\
SNU-638 & 9.1 & 1.0 \\
HCT-116 & 3.8 & 0.9 \\
HT-1080 & 1.1 & 0.9 \\
\hline
\end{tabular}

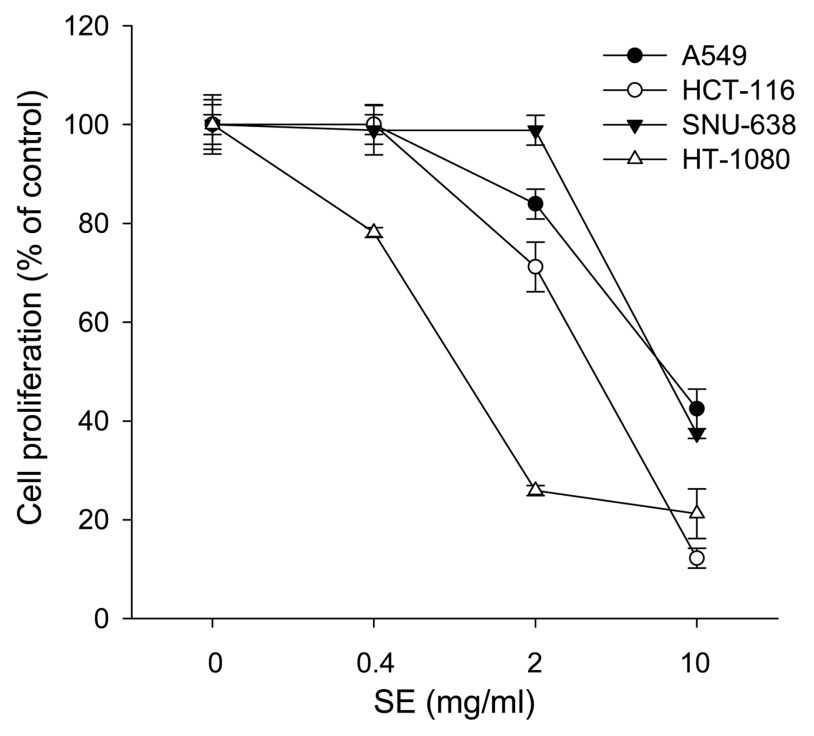

Fig. 2. Inhibitory effects of strawberry extracts (SE) on the proliferation of various human cancer cells. Cells were incubated with various concentrations of strawberry extracts (SE) for 72 h. After incubation, cells were fixed with $50 \%$ trichloroacetic acid solution, and then stained with $0.4 \%$ sulforhodamine B (SRB) solution. Stained cells were dissolved in Tris buffer $(\mathrm{pH}$ 10.0), and absorbance was measured at $515 \mathrm{~nm}$. Proliferation of each concentration was determined by comparison with vehicle-treated control cells.

positive control of non-selective inhibitor of NOS (Leiper and Vallance, 1999), exhibited an $\mathrm{IC}_{50}$ of $34 \mu \mathrm{M}$ (data not shown). When the cells were simultaneously treated with various concentrations of SE and LPS, NO production was significantly inhibited in a dose-dependent manner with an $\mathrm{IC}_{50}$ value of $2.1 \mathrm{mg} / \mathrm{ml}$ (Fig. 3). No significant effect on cell viability was observed at a test concentration up to $5 \mathrm{mg} / \mathrm{ml}$ SE as determined by MTT assay ( $>95 \%$ cell survival).

To elucidate the mechanisms of action of SE on the inhibition of NO production, further study was performed. Since the accumulation of NO by LPS treatment in macrophages is highly correlated to the enhanced expression of iNOS protein and mRNA (Geller et al., 1993; 


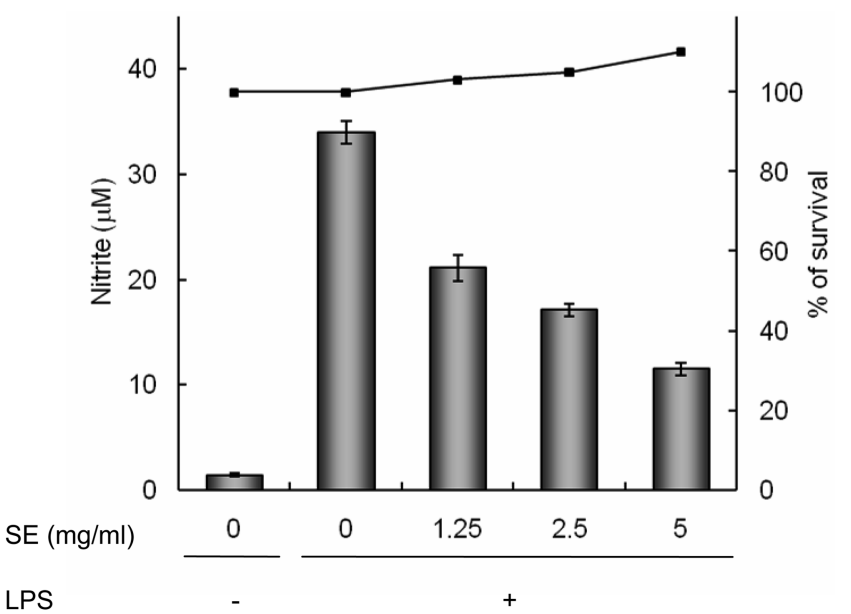

Fig. 3. Inhibitory effects of strawberry extracts (SE) on lipopolysaccharide (LPS)-induced nitric oxide (NO) production. RAW 264.7 cells $\left(5 \times 10^{5}\right.$ cells $\left./ \mathrm{ml}\right)$ were incubated in 24 well plates for $24 \mathrm{~h}$, then stimulated by the treatment of LPS $(1 \mu \mathrm{g} /$ $\mathrm{ml}$ ) with or without strawberry extracts $(1.25-5 \mathrm{mg} / \mathrm{ml})$. After 20 $\mathrm{h}$, the media were collected and examined the amount of $\mathrm{NO}$ production using colorimetric Griess reaction. The data were expressed as mean \pm S.E.M. of triplicate test.

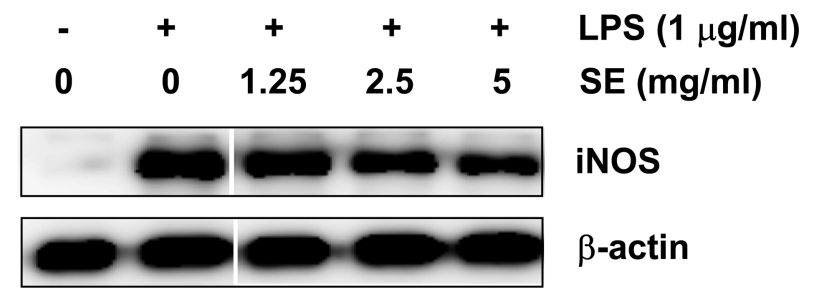

Fig. 4. Inhibitory effects of strawberry extracts (SE) on the expression of inducible nitric oxide synthase (iNOS) protein. RAW 264.7 cells stimulated with lipopolysaccharide (LPS) (1 $\mu \mathrm{g} / \mathrm{ml})$ with or without strawberry extracts $(1.25-5 \mathrm{mg} / \mathrm{ml})$ for 4 h. Western blot analysis was subjected for the iNOS protein expression and data were representative of three separated experiments.

Lyons et al., 1992; Schmidt et al., 1992), the effects of SE on the iNOS protein and gene expression were determined. As shown in Fig. 4 , the treatment of LPS $(1 \mu \mathrm{g} / \mathrm{ml})$ for $16 \mathrm{~h}$ markedly enhanced expression of iNOS protein, and this effect was diminished by the co-treatment of SE $(1.25-5 \mathrm{mg} / \mathrm{ml})$ in a dose-dependent manner. To further investigate the effect of SE on LPS-induced iNOS mRNA levels, steady-state levels of iNOS mRNA were determined using RT-PCR analysis. As shown in Fig. 5, SE moderately decreased the levels of iNOS mRNA induced by LPS, suggesting that the inhibitory activity of iNOS by SE might be correlated to the suppression of iNOS gene and protein expression.

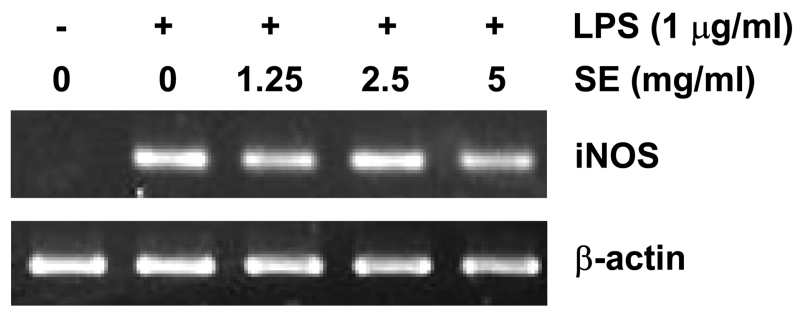

Fig. 5. Inhibitory effects of strawberry extracts (SE) on the expression of inducible nitric oxide synthase (iNOS) mRNA. RAW 264.7 cells stimulated with lipopolysaccharide (LPS) (1 $\mu \mathrm{g} / \mathrm{ml})$ with or without strawberry extracts $(1.25-5 \mathrm{mg} / \mathrm{ml})$ for 4 h. iNOS mRNA expression was determined by RT-PCR analysis, and data were representative of three separated experiments.

\section{DISCUSSION}

Recently, there have been many reports which postulate the relevance between the ROS and other inflammatory mediators with various diseases, leading to much attention for natural products with antioxidative and antiinflammatory activities. Especially, phenolic compounds in natural products possess various pharmacological properties such as antioxidative, antimutagenic, and anticancer potentials. Thus, allowing possibilities in the development of agents are effective for the cardiovascular disease and prevention and cure of the cancer. In strawberry, beyond saccharides, several phenolic compounds including ellagic acid and flavonoids (anthocyanin, catechin, quercetin and kaempferol, etc.) are also abundant (Häkkinen et al., 2000; Sandra and Hannum, 2004). These compounds in strawberries might be related to the biological activities of its antioxidant and anticancer properties (Bors and Saran, 1987; Das, 1994; Laranjinha et al., 1994; Sandra and Hannum, 2004; Wang et al., 1996). Although several biological activities were reported using western strawberries there is no significant information for the pharmacological activities using Korean domestic strawberry cultivar. Therefore, in this study, we tried to provide implicative information for the biological activities with the Korean strawberry cultivar of Maehyang. Primarily, studies regarding the biological activities such as scavenging free radicals, suppressing pro-inflammatory processes, and inhibiting proliferation against human cancer cells of the Maehyang strawberry cultivar were conducted. Oxidative stress has been implicated in an enormous variety of physiological and pathological processes. An oxidation-reduction imbalance in a healthy living system leads to malfunctioning of cells that can ultimately result in various diseases, including aging, cancer, neurological degeneration, and 
arthritis. Thus, in this study, we examined antioxidant potential of strawberry extract of Maehyang (SE) by the use of DPPH that stably generates free radicals in ethanol solution. As a result, SE showed free radical scavenging activities in a dose-dependent manner. Strawberries have been shown to exhibit high total antioxidant capacity in comparison to many other fruits (Wang et al., 1996), and this antioxidant activity has been shown to vary among different species. Therefore, comparison of antioxidant activity among other domestic strawberry cultivars would be interesting and may provide beneficial information. Since increased NO production and overexpression of inducible nitric oxide synthase (iNOS) are considered to be strongly related to the pathogenesis of several diseases including inflammation and carcinogenesis, regulation of iNOS in cells might be important for the treatment of inflammation and carcinogenesis (Chan et al, 1998; Hobbs et al, 1999; Kawamori et al, 1999; Rao et al, 2000). The present results demonstrate that strawberry inhibits the production of NO in LPS-activated RAW 264.7 macrophage cells in a dose-dependent manner, and subsequent study revealed that the inhibitory effect of strawberry on NO production was highly related to the suppression of iNOS protein and gene expression as assessed by Western and RT-PCR analysis. Furthermore, strawberry extracts have been shown to inhibit the expression of COX-2 mRNA in vitro, which would modulate the inflammatory process (data not shown). COX-2, which produces $P \mathrm{PE}_{2}$, is induced by the response of several pro-inflammatory stimuli such as bacterial lipopolysaccharide (LPS), interleukn-1 (IL-1), and interferon- $\gamma$ (IFN- $\gamma$ ) (Duois et al., 1998; Kröncke et al., 1998). In many previous studies, phenolic compounds in the strawberry were reported to have suppressive effect for cancer progression. We therefore evaluated the growth inhibition, activity of SE against cancer cells including human lung, stomach, colon and fibrosarcoma cells. SE also inhibited the proliferation of cancer cells tested in a dose-dependent matter. In a previous study by Xue et al., freezedried extracts of strawberries exhibited the potent chemopreventive activity which appears to involve cellular transformation and interference of uptake, activation, detoxification, and/or intervention of DNA binding and DNA repair (Xue et al., 2001). Therefore, the anti-proliferative effect of SE might be valuable information in relation to the chemopreventive potential of SE in cancer cells.

In summary, we evaluated, for the first time, the biological activities of the extracts of Maehyang cultivar, a Korean domestic strawberry, using in vitro assay systems. The extracts exhibited antioxidant effects by free radical scavenging activities. The SE also possesses the anti-inflammatory activity with the suppression of LPSinduced NO production and iNOS gene expression in macrophage cells. Anti-proliferative effects of human cancer cell growth by SE might also be valuable information in the control of cancer. These findings provide additional pharmacological information of Korean domestic strawberry cultivar Maehyang extracts as useful sources for the development of functional foods.

\section{ACKNOWLEDGMENTS}

This study was supported in part by the grant No.20070401-080-084 from the Biogreen 21 Project of Rural Development Administration.

\section{REFERENCES}

Alley, M. C., Dominic, A. and Shoemaker, R. H. (1998). Feasibility of drug screening with panels of human tumor cell lines using a microculture tetrazolium assay. Cancer Res. 48, 589601.

Ames, B. N., Shigenaga, M. K. and Hagen, T. M. (1993). Oxidants, antioxidants, and the degenerative disease of aging. Proc. Natl. Acad. Sci. 90, 7915-7922.

Bors, W. and Saran, M. (1987). Radical scavenging by flavonoid antioxidants. Free Radical Res. Commun. 2, 289-294.

Chan, M. M., Huang, H. I., Fenton, M. R. and Fong, D. (1998). In vivo inhibition of nitric oxide synthase gene expression by curcumin, a cancer chemopreventive natural product with anti-inflammatory properties. Biochem. Pharmacol. 55, 19551962.

Das, D. K. (1994). Naturally occurring flavonoids: structure, chemistry, and high-performance liquid chromatography methods for separation and characterization. Methods Enzymol. 234, 411-421.

Dreher, D. and Junod, A. F. (1998). Role of oxygen free radicals in cancer development. Eur. J. Cancer 32A, 30-38.

Dubois, R. N., Gupta, R., Brockman, J., Reddy, B. S., Krakow, S. L. and Lazar, M. A. (1998). The nuclear eicosanoid receptor, PPARgamma, is aberrantly expressed in colonic cancers. Carcinogenesis 19, 49-53.

Geller, D. A., Kussler, A. K., DiSilvio, M., Lowenstein, C. J., Shapiro, R. A., Wang, S. C., Simmons, R. L. and Billar, T. R. (1993). Cytokines, endotoxin and glucocorticoids regulate the expression of inducible nitric oxide synthase in hepatocytes. Proc. Natl. Acad. Sci. 90, 522-526.

Green, L. C., Wanger, D. A., Glogowski, J., Skipper, P. L., Wishnok, J. S. and Tannenbaum, S. R. (1982). Analysis of nitrate, nitrite, and $\left[{ }^{15} \mathrm{~N}\right]$ nitrate in biological fluids. Anal. Biochem. 126, 131-138.

Häkkinen, S. H., Kärenlampi, S. O., Mykkänen, H. M., Heinone, I. M. and Törrönen, A. R. (2000). Ellagic acid content in Berries: Influence of domestic processing and storage. Eur. Food Res. Technol. 212, 75-80. 
Heinonen, M. I., Meyer, A. S. and Frankel, E. N. (1998). Antioxidant activity of berry phenolics on human low-density lipoprotein and liposome oxidation. J. Agric. Food Chem. 46, 41074112.

Hobbs, A. J., Higgs, A. and Moncada, S. (1999). Inhibition of nitric oxide synthase as a potential therapeutic target. Annu. Rev. Parmacol. Toxicol. 39, 191-220.

Kawamori, T., Lubet, R., Steele, V. E., Kelloff, G. J., Kaskey, R. B., Rao, C. V. and Reddy, B. S. (1999). Chemopreventive effect of curcumin, a naturally occurring anti-inflammatory agent, during the promotion/progression stages of colon cancer. Cancer Res. 59, 597-601.

Kröncke, K. D., Fehsel, K. and Kolb-Bachofen, V. (1998). Inducible nitric oxide synthase in human diseases. Clin. Exp. Immunol. 113, 147-156.

Lee, S. K., Mbwambo, Z. H., Chung, H., Luyengi, L., Gamez, E. J. C., Mehta, R. G., Kinghorn, A. D. and Pezzuto, J. M. (1998). Evaluation of the antioxidant potential of natural products. Comb. Chem. High T. Scr. 1, 35-46.

Lander, H. M. (1997). An essential role for free radicals and derived species in signal transduction. FASEB J. 11, 118-124.

Laranjinha, J. A., Almeida, L. M. and Madeira, V. M. (1994). Reactivity of dietary phenolic acids with peroxyl radicals: antioxidant activity upon low density lipoprotein peroxidation. Biochem. Phrmacol. 48, 487-494.

Leiper, J. and Vallance, P. (1999). Biological significance of endogenous methylarginines that inhibit nitric oxide synthases. Cardiovasc. Res. 43, 542-548.

Lyons, C. R., Orloff, G. J. and Cunningham, J. M. (1992). Molecular cloning and functional expression of an inducible nitric oxide synthase from a murine macrophage cell line. J. Biol. Chem. 267, 6370-6374.

Meyskens, F. L. and Szabo, E. (2005). Diet and cancer: the disconnect between epidemiology and randomized clinical trials. Cancer Epidemiol. Biomarkers Prev. 14, 1366-1369.

Ohshima, H. and Bartsch, H. (1994). Chronic infections and inflammatory processes as cancer risk factors: possible role of nitric oxide in carcinogenesis. Mutat. Res. 305, 253-264.

Patel, R. P., Moelliring, D., Murphy-Ullrich, J., Jo, H., Beckman, J. S. and Darley-Usmar, V. M. (2000). Cell signaling by reactive nitrogen and oxygen species in atherosclerosis. Free Radic. Biol. Med. 28, 1780-1794.
Rao, C. V., Indranie, C., Simi, B., Manning, P. T., Connor, J. R. and Reddy, B. S. (2002). Chemopreventive properties of a selective inducible nitric oxide synthase inhibitor in colon carcinogenesis, administered alone or in combination with celecoxib, a selective cyclooxygenese-2 inhibitor. Cancer Res. 62, 165-170.

Sandra, M. and Hannum, M. R. (2004) Potential impact of strawberries on human health: A review of the sceince. Crit. Rev. Food Sci. Nutr. 44, 1-17.

Schmidt, H. H., Warner, T. D., Nakane, M., Fostermann, U. and Murad, F. (1992). Regulation and subcellular location of nitrogen oxide synthases in RAW 264.7 macrophages. Mol. Pharmacol. 41, 615-624.

Skehan, P., Storeng, R., Scudiero, D. Monks, A., McMahon, J., Vistica, D., Warren, J. T., Bokesch, H., Kenney, S. and Boyd, M. R. (1990). New colorimetric cytotoxicity assay for anticancer-drug screening. J. Natl. Cancer Inst. 82, 1107-1112.

Steinmetz, K. A. and Potter, J. D. (1991). Vegetable, fruit and cancer. Cancer Causes Control 2, 325-357.

Sun, J., Chu, Y. F., Wu, X. and Liu, R. H. (2002). Antioxidant and antiproliferative acitivities of common fruits. J. Agric. Food Chem. 50, 7449-7454.

Temple, N. J. (2000). Antioxidants and disease: more questions than answers. Nutr. Res. 20, 449-459.

Vinson, J. A., Su, X., Zubik, L. and Bose, P. (2001). Phenol antioxidant quantity and quality in foods: Friut. J. Agric. Food Chem. 49, 5315-5321.

Willett, W. C. (1994). Diet and health: what should we eat. Science 254, 532-537.

Wang, H., Cao, G. and Prior, R. L. (1996). Total antioxidant capacity of fruits. J. Agric. Food Chem. 44, 701-705.

Wang, H., Cao, G. and Prior, R. L. (1997). Oxygen radical absorbing capacity of anthocyanins. J. Agric. Food Chem. 45, 304-309.

Wiseman, H. and Halliwell, B. (1996). Damage to DNA by reactive oxygen and nitrogen species: role in inflammatory disease and progression to cancer. J. Biol. Chem. 269, 47054708.

Xue, H., Aziz, R. M., Sun, N., Cassady, J. M., Kamendulis, L. M., Xu Y., Stoner, G. D. and Klaunig, J. E. (2001). Inhibition of cellular transformation by berry extracts. Carcinogenesis $\mathbf{2 2}$, 351-356. 